\title{
Composition and Thickness of Surface Layer on Molybdenum Tips for Scanning Tunnelling Microscopy (STM) Studied by SEM/AES/(AR)XPS
}

\author{
W. Lisowski, ${ }^{1 *}$ A. H. J. van den Berg, ${ }^{2}$ L. J. Hanekamp ${ }^{1,2} \dagger$ and A. van Silfhout ${ }^{1}$ \\ ${ }^{1}$ Faculty of Applied Physics, University of Twente, PO Box 217, NL-7500 AE Enschede, Netherlands \\ ${ }^{2}$ Centre of Materials Research, University of Twente, PO Box 217, NL-7500 AE Enschede, Netherlands
}

\begin{abstract}
A combination of SEM, AES and angle-resolved XPS (ARXPS) bas been applied to analyse the distribution of chemical compounds in the surface region of electrochemically etched molybdenum tips and to determine the contamination layer thickness. Carbon monoxide, graphite, molybdenum carbide and molybdenum oxide were found to be the main surface contaminants on molybdenum tips. Auger line profiling revealed a significant enrichment of carbon and oxygen upon the tip. The thickness of the oxygen-carbon contamination layer on the tip was estimated to be $13.5 \pm 1.0 \mathrm{~nm}$ as measured by AES. The thickness of the contamination layer on a molybdenum sheet was found to be $8.0 \pm 1.5$ and $6.8 \mathrm{~nm}$ using AES and ARXPS respectively. Quantitative analysis of the surface concentrations of carbon, oxygen and molybdenum has been performed.
\end{abstract}

\section{INTRODUCTION}

The scanning tunnelling microscope (STM) is a useful tool for real-space imaging of near-surface electronic structure. ${ }^{1,2}$ The reliable formation of fine and clean tunnelling probe tips is one of the most important experimental aspects of STM operation. It is well known that a surface contamination layer can influence the tunnelling current by changing the effective resistance of the tip surface layer. ${ }^{3,4}$ Therefore it is of great interest to know the composition and thickness of such layers.

Unfortunately, only a few papers deal with the analysis of the surface composition of STM tips. The AES technique has been applied in the analysis of $\mathrm{Pt} / \mathrm{Ir}^{5}$ and $\mathrm{W}^{6}$ tips. The XPS method has been employed for the determination of graphite ${ }^{7}$ and tungsten ${ }^{6}$ tip surface compositions.

The thickness of the surface contamination layers on STM tips has been determined using TEM ${ }^{4,8,9}$ and AES combined with $\mathrm{Ar}^{+}$sputter profiling. ${ }^{6}$

There is a lack of surface characterization of molybdenum tips which are often utilized in STM. ${ }^{10,11}$

The purpose of the present paper is to elucidate both the chemical structure and distribution of chemical compounds in the surface region of electrochemically etched STM molybdenum tips and to determine the contamination layer thickness. A combination of SEM, AES and XPS has been applied for the chemical characterization of the surface layer. The surface of the Mo STM tip contamination layer has been characterized using AES combined with $\mathrm{Ar}^{+}$sputter profiling and

- Permanent address: Institute of Physical Chemistry, Polish Academy of Sciences, ul Kasprzaka 44/52, 01-224, Warszawa, Poland.

† Author to whom correspondence should be addressed. angle-resolved XPS (ARXPS). The combination of these methods, applied for the first time to Mo tip analysis, allowed us to make a full characterization of the Mo tip surface.

\section{EXPERIMENTAL}

Electrochemically etched molybdenum tips were fabricated by placing several millimetres of $0.7 \mathrm{~mm}$ colddrawn molybdenum wire into a $1 \mathrm{M} \mathrm{KOH}$ etching solution and applying a $12 \mathrm{~V}_{\text {eff }}, 50 \mathrm{~Hz}$ potential to the molybdenum wire (with respect to a gold ring electrode surrounding the Mo wire and inserted into the solution). At the end of the etching procedure the poterltial was reduced to $6 \mathrm{~V}$ a.c. to obtain a sharper tip. The etching process was discontinued when the suspended wire fell off. This wire was then cleaned in distilled water and directly transported in air to the measuring system.

Two methods have been used to characterize the composition and elemental distribution in the surface region of the Mo tip, i.e. Auger line scans and multiplepoint $\mathrm{Ar}^{+}$-ion-sputtering Auger depth profiles. The measurements have been performed with a PHI 600 SAM (scanning Auger microscope) system.

The elemental Auger line scans were recorded using the following experimental conditions: a primary beam, directed perpendicular to the axis of the wire, of energy $E_{\mathrm{p}}=15 \mathrm{kV}$; primary beam current $I_{\mathrm{p}}=0.25 \mathrm{nA}$; beam diameter $\varnothing \approx 30 \mathrm{~nm} ; 100$ points per line; analysis time per point, $\tau=25 \mathrm{~s}$. The resolution of the cylindrical mirror analyser, $\Delta E / E$, was set at $1.2 \%$. Under these conditions the detection limits for carbon and oxygen are less than $2 \%$ and $0.5 \%$ (atomic concentration) respectively. ${ }^{12}$ The line scans have been corrected for topographic effects by taking the normalized Auger 
intensity $(P-B) / B$, where $P$ and $B$ are the peak and background intensities respectively. ${ }^{13}$

The Auger spectra and Auger sputter profiles were taken using $E_{\mathrm{p}}=10 \mathrm{kV} ; I_{\mathrm{p}}=0.1 \mu \mathrm{A}, \varnothing \approx 0.4 \mu \mathrm{m}$ and $\Delta E / E=0.6 \%$. The axes of the wire, electron beam and ion beam were oriented in one plane. The angles between the axis of the wire and the electron beam and ion beam were $90^{\circ}$ and $160^{\circ}$ respectively. The argon ion beam, with an ion energy of $3.5 \mathrm{kV}$ and a current density of $0.6 \mu \mathrm{A} \mathrm{cm}{ }^{-2}$, was produced by a differentially pumped ion gun. Calibration of the sputter rate was performed on a $\mathrm{Ta}_{2} \mathrm{O}_{5}$ layer of thickness $100 \mathrm{~nm}$.

The XPS and ARXPS experiments were carried out in a Kratos 800 system controlled by a PDP 11 microcomputer. The spectrometer was calibrated by measuring the $\mathrm{Ag} 3 \mathrm{~d}_{5 / 2}$ peak and the x-ray-induced $\mathrm{Ag}$ MNN Auger peak on a clean, sputtered silver sample using an $\mathrm{Mg}$ anode ${ }^{14}$ and its linearity was checked. The analysed area was about $0.2 \mathrm{~mm}^{2}$ by using a diaphragm and comprised both the tip and the surrounding areas. The spectra were taken and quantitatively evaluated using DS 800 software. $^{15}$ In all simulations the asymmetrical Gaussian-Lorentzian mixed functions were used for the molybdenum peaks and $100 \%$ Gaussians for the oxide and carbide peaks. Such curve synthesis of Mo x-ray photoelectron spectra has been reported by Kojima and Kurahashi $^{16}$ to be sufficiently flexible to represent an XPS peak.

\section{RESULTS AND DISCUSSION}

\section{AES measurements}

Figure 1 shows an SEM image of a molybdenum tip on which analysis has been done.

The Auger spectrum of the STM molybdenum tip in the surface region is presented in Fig. 2. It reveals

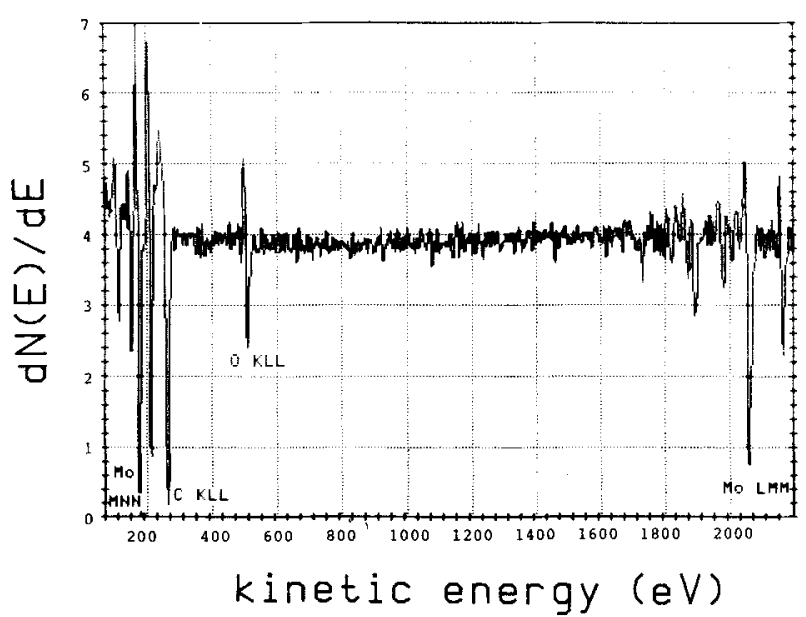

Figure 2. Auger spectrum of molybdenum STM tip surface before $\mathrm{Ar}^{+}$sputtering.

oxygen and carbon in addition to molybdenum. The Auger line scans in Fig. 3 display the topographically corrected carbon and oxygen Auger intensities along the tip in the SEM image (Fig. 1, indicated by arrows).

It can be seen that the oxygen and carbon concentrations are not homogeneous in the measuring area ( $0-2$ $\mu \mathrm{m}$ ). A significant enrichment (relative atomic concentration) of both elements is detected at the top of the Mo tip. This could be due to carbon and oxide formation as a result of the high local temperature generated during the formation of the tip at the end of the electrochemical etching procedure.

In order to get a better insight to the distribution and thickness of carbon and oxygen contamination, multiple-point $\mathrm{Ar}^{+}$-ion-sputtering Auger depth profiles have been measured on both the Mo tip and a largearea Mo sheet of the same material after the same electrochemical etching and cleaning procedure. The results

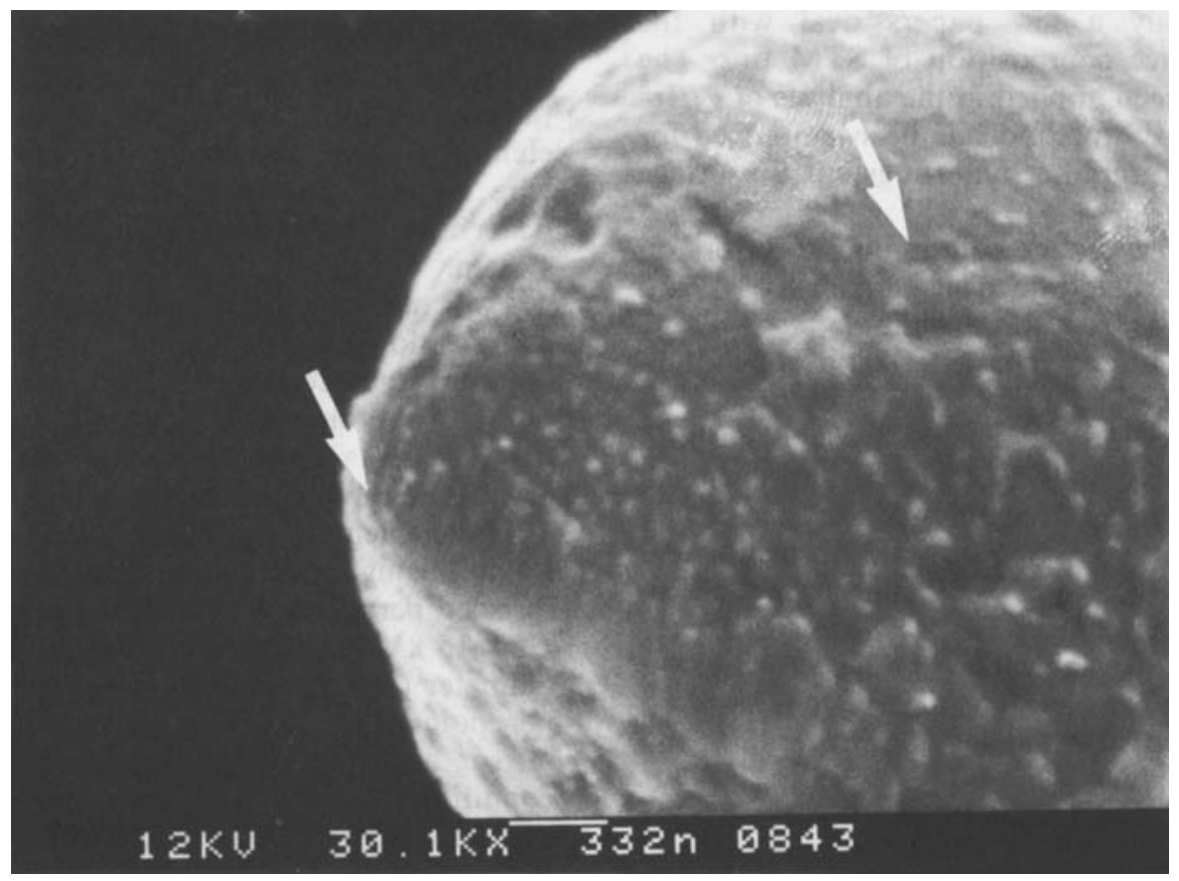

Figure 1. Scanning electron micrograph of electrochemically etched molybdenum STM tip analysed by AES. 


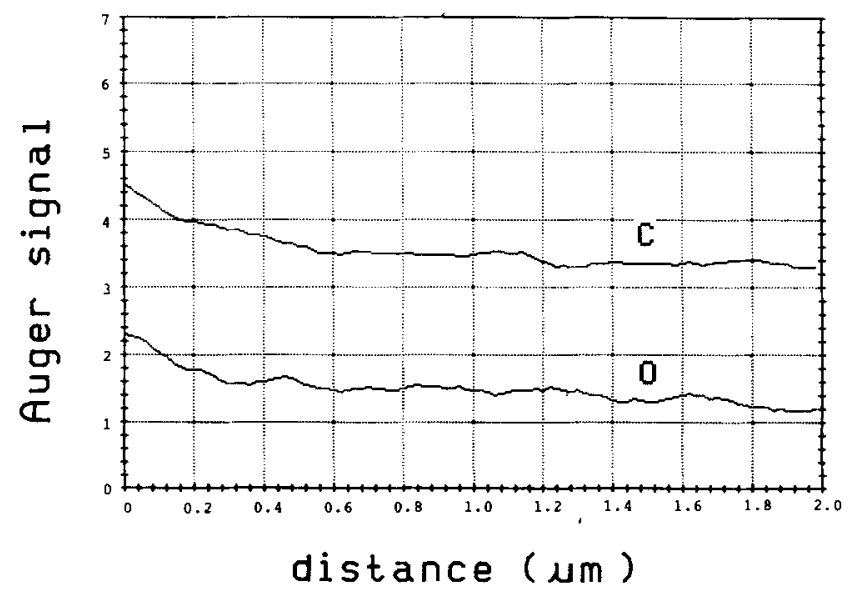

Figure 3. Auger elemental line scans recorded between the two arrows in the SEM image of Fig. 1. The Auger signal is given in arbitrary units.

are presented in Fig. 4. The peak-to-peak heights of the Mo MNN, C KLL and O KLL Auger peaks, divided by the standard sensitivity factors, ${ }^{17}$ have been plotted in atomic concentration mode as a function of sputter time.

It can be seen that the time required for sputtering of oxygen and carbon from the tip [Fig. 4(a)] is significantly longer than that recorded on the Mo sheet [Fig. 4(b)].

The calculation of the thickness must be done very carefully. For a rough calculation a linear relation between sputtering time and removed layer may be

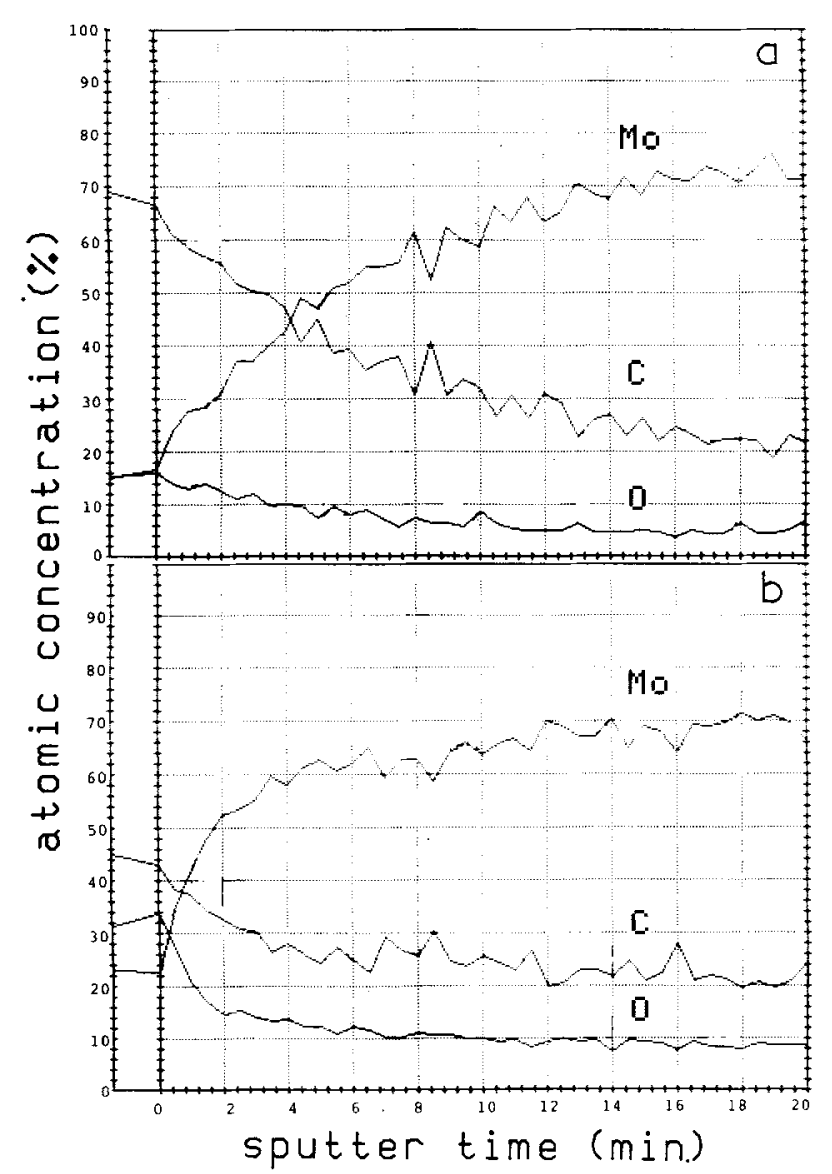

Figure 4. Auger sputter depth profiles (a) molybdenum STM tip and (b) Mo sheet. Sputter rate $0.8 \mathrm{~nm} \mathrm{~min}{ }^{-1}$. assumed. In our system the sputter rate was found to be $0.8 \mathrm{~nm} \mathrm{~min} \min ^{-1}$ by calibration performed on a $\mathrm{Ta}_{2} \mathrm{O}_{5}$ layer. On the basis of the fact that the surface-binding energy for tantalum and molybdenum ${ }^{18}$ as well as the sputter yield ${ }^{19}$ and depth resolution for Ar profiling of $\mathrm{Ta}$ and $\mathrm{Mo}^{20}$ are similar, we can use the above value of the sputter rate to estimate the molybdenum oxidecarbon layer thickness. The influence of the ion- and electron-induced effects accompanying AES depth profile measurements ${ }^{21}$ seems to be comparable for thin Ta and Mo layers and has been neglected.

The thickness of the molybdenum oxide-carbon layer on the Mo tip and Mo sheet was estimated to be $13.5 \pm 1.0$ and $8.0 \pm 1.5 \mathrm{~nm}$ respectively. The latter value has been verified by comparison with the results of the ARXPS measurements.

Analysis of the $\mathrm{Ar}^{+}$-ion-sputtering Auger depth profiles afforded the possibility of comparing the character of carbon and molybdenum compounds in the bulk and in the surface region of the Mo tip. Figure 5 shows the C KLL and Mo MNN Auger lines before and after 16 $\mathrm{nm}$ depth sputtering of the Mo tip.

The C KLL spectrum peaks at 273, 254 and $241 \mathrm{eV}$ suggest the graphitic nature of carbon in the surface region of the Mo tip as reported by Haas et al. ${ }^{22}$ The shift of the C KLL Auger peak at $273 \mathrm{eV}$ to lower energies after sputtering and the shape of the Auger lines [Fig. 5(a)] seem to be indicative of the carbide character of carbon in the bulk. ${ }^{22}$ Similar features in the carbon Auger spectrum have been observed on an electrochemically etched tungsten STM tip. ${ }^{6}$

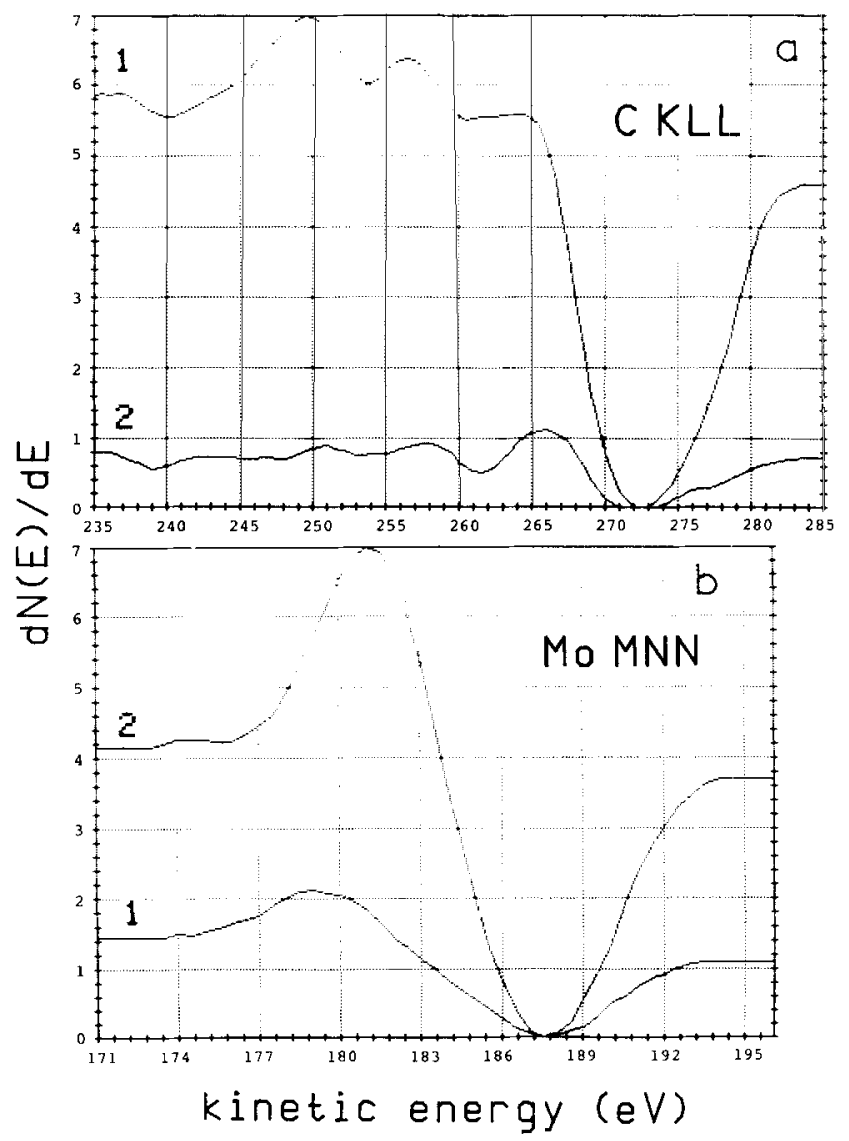

Figure 5. AES lines in the differentiated mode for (a) C KLL and (b) Mo MNN of the molybdenum tip before (lines 1) and after (lines 2) $16 \mathrm{~nm} \mathrm{Ar}^{+}$sputtering. 
The broad Mo MNN Auger peak was recorded before sputtering [Fig. 5(b)]. This shape of spectrum has been reported for oxidized molybdenum and was interpreted to be due to the presence of two valence states of Mo giving overlapping spectra separated in energy by about $4 \mathrm{eV} .^{22}$ The observed $4 \mathrm{eV}$ shift in energy of the lower-kinetic-energy maximum of the Mo MNN spectrum due to sputtering [Fig. $5(\mathrm{~b})]$ appears to confirm the existence of an oxidized molybdenum state on the Mo tip.

\section{XPS measurements}

Figure 6 shows the XPS spectra of Mo 3d, C 1s and O 1s of the STM molybdenum tip. Two Gaussians and one Lorentzian-Gaussian doublets were used in the deconvolution of the Mo 3d spectrum, whereas pure Gaussians were applied in the simulation of the $\mathrm{C} 1 \mathrm{~s}$ and $O 1 \mathrm{~s}$ peaks. The thinner lines represent the deconvoluted peaks. The sum of these lines is given as the thicker solid line.

The binding energy (BE) of the Mo $3 d_{5 / 2}$ signal $(228.0 \mathrm{eV})$ was found to be close to that reported by other authors (Table 1). Quantitative evaluation and deconvolution of the Mo $3 \mathrm{~d}$ spectrum revealed additional peaks at $\mathrm{BE}=229.8$ and $228.3 \mathrm{eV}$ [Fig. 6(a)]. On the basis of the results of the fitting procedure and comparing these results with the binding energies reported earlier for some molybdenum compounds (Table 1), we

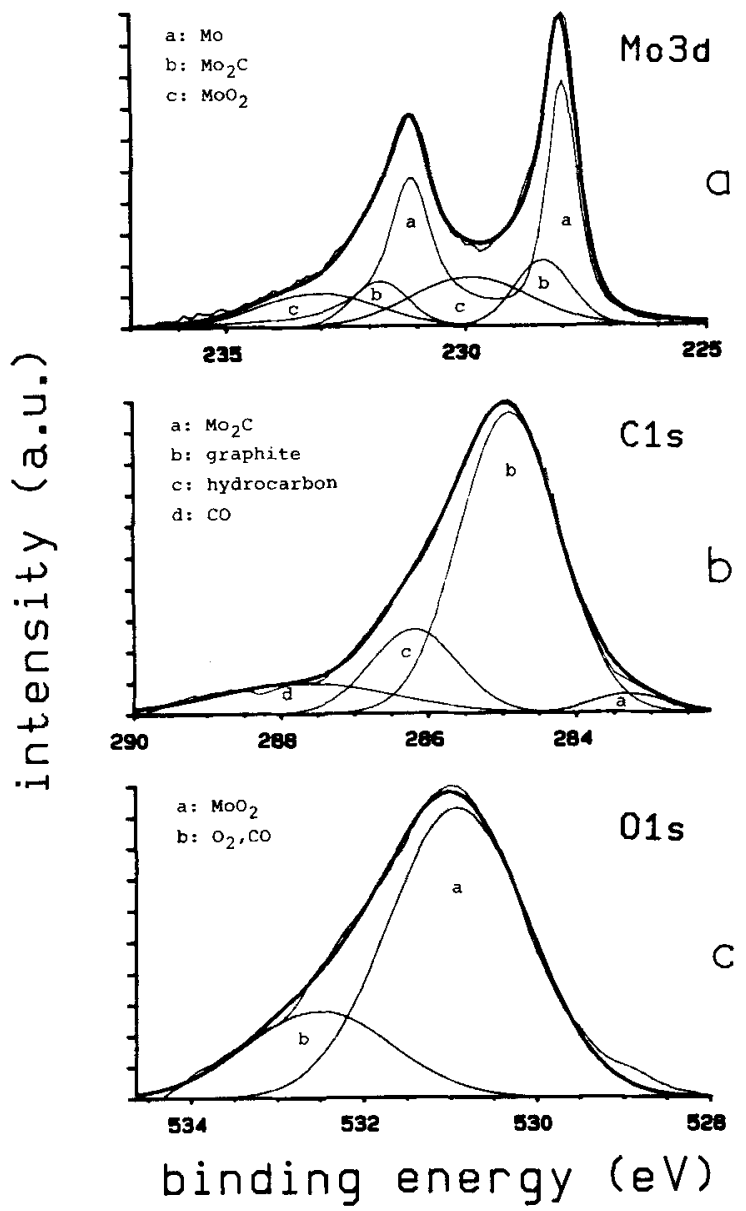

Figure 6. (a) Mo 3d, (b) $C$ is and (c) $O$ is XPS spectra of molybdenum STM tip. Deconvoluted peaks are described in the graphs. can confirm the coexistence of $\mathrm{Mo}, \mathrm{MoO}_{2}$ and $\mathrm{Mo}_{2} \mathrm{C}$ in the surface region of molybdenum tips.

The $\mathrm{C}$ 1s spectrum presented in Fig. $6(\mathrm{~b})$ discloses the existence of four XPS peaks at 283.2, 284.9, 286.2 and $287.7 \mathrm{eV}$ which can be attributed to molybdenum carbide, ${ }^{24,39,40}$ graphite, ${ }^{41}$ hydrocarbon carbon ${ }^{42}$ and molecular adsorbed $\mathrm{CO} .{ }^{43}$ The interpretation can also be based on three different states of $\mathrm{CO}$ adsorption ( $\beta$ at $282.7 \mathrm{eV}, \alpha$ at $288 \mathrm{eV}$ and 'virgin' at $284.6 \mathrm{eV}$ ) on polycrystalline $\mathrm{Mo}^{43}$ Nevertheless, application of the 'virgin' state formed at $77 \mathrm{~K}^{43}$ seems to be rather doubtful in our case.

Similar analysis of the $O 1 \mathrm{~s}$ spectrum [Fig. 6(c)] reveals the existence of XPS peaks at 530.9 and 532.5 eV which can be attributed to $\mathrm{MoO}_{2}$ or $\mathrm{MoO}_{3}$ (Table 1) and chemisorbed $\mathrm{O}_{2}$ and $\mathrm{CO}^{43}$ respectively.

The results of quantitative evaluation of $\mathrm{C}, \mathrm{O}$ and Mo concentrations are presented in Table 2. Relatively high concentrations of carbon were found by XPS and AES on both tips and sheets. Nevertheless, the resulting concentrations of $\mathrm{C}$ determined by XPS are lower than those established by AES. This discrepancy can be explained by the difference in the mean free path for inelastic scattering of emitted electrons. ${ }^{14}$ In XPS the escape energy ( $h v-\mathrm{BE}$ ) for Mo $3 \mathrm{~d}$ is about $1027 \mathrm{eV}$ whereas the emission energy of the Mo MNN Auger peak is about $186 \mathrm{eV}$. Therefore in this case the XPS method seems to be slightly less surface-sensitive than AES. The results of ARXPS measurements performed at $60^{\circ}$, which revealed a significant enrichment of carbon in the surface region of the Mo sheet (Table 2), appear to confirm the above suggestion.

The concentrations (atomic per cent) of Mo, C and O in the different compositions obtained from XPS measurements on the Mo sheet are given in Table 3. This enables us to cross-check the mass balance for $\mathrm{MoO}_{2}$ and $\mathrm{Mo}_{2} \mathrm{C}$. The results for $\mathrm{MoO}_{2}$ are in good agreement and those for $\mathrm{Mo}_{2} \mathrm{C}$ in reasonable agreement.

\section{ARXPS measurements}

The non-destructive ARXPS method is used often to study the thickness of the outermost top layer of solid materials. ${ }^{44}$ We have applied 'absolute' ARXPS measurements described recently by Aarnink et al. ${ }^{44}$ In this method the same XPS peak is measured at various photoelectron take-off angles and its intensity is normalized to the normal take-off angle.

For the intensity of the XPS peak of molybdenum measured at different electron take-off angles $(\alpha)$ and normalized to its intensity at normal take-off angle $(\alpha=0)$ we may write 44

$$
\begin{aligned}
N(\alpha) & =\frac{I_{\mathrm{Mo} \mathrm{3d}}(\alpha)}{I_{\mathrm{Mo} \mathrm{3d}}(0)} \\
& =G(\alpha) \exp \left[\frac{d}{\lambda_{\mathrm{Mo} \mathrm{3d}, \text { surf }}}\left(1-\frac{1}{\cos \alpha}\right)\right]
\end{aligned}
$$

where $d$ is the uniform thickness of the surface layer and $\lambda_{\text {Mo 3d, surf }}$ represents the inelastic mean free path of the photoelectrons in this layer.

The function $G(\alpha)$, which depends on the geometry of the experimental set-up, sample and sample holder, has been measured directly on a clean, sputtered silver 
Table 1. Mo $3 \mathrm{~d}_{5 / 2}, \mathrm{C}$ 1s and $\mathrm{O}$ 1s binding energies (eV) of some selected molybdenum compounds

\begin{tabular}{|c|c|c|c|c|c|c|}
\hline Level & Mo & $\mathrm{Mo}_{2} \mathrm{C}$ & $\mathrm{MoO}_{2}$ & $\mathrm{MoO}_{3}$ & $\begin{array}{c}\text { Reference standard } \\
\text { Au } 4 f_{7 / 2}=84.0 \mathrm{eV} \\
\mathrm{Cu} 2 \mathrm{p}_{3 / 2}=932.7 \mathrm{eV} \\
\text { C 1s }=285.0 \mathrm{eV}\end{array}$ & Ret. \\
\hline \multirow[t]{16}{*}{ Mo $3 d_{5 / 2}$} & 227.5 & & 228.8 & 232.2 & $\mathrm{Au}$ & 23 \\
\hline & 227.6 & 227.8 & & & Au & 24 \\
\hline & 227.6 & & 229.4 & 232.6 & Au & 25 \\
\hline & 227.9 & & & 232.85 & $\mathrm{Au}, \mathrm{Cu}$ & 26 \\
\hline & 227.9 & & 229.5 & & Au & 27 \\
\hline & 227.94 & & & & $\mathrm{Au}$ & 28 \\
\hline & 228.0 & & 232.0 & 232.7 & Au & 29 \\
\hline & 228.0 & & 229.3 & 232.7 & Au & 30 \\
\hline & 228.0 & & & & $\mathrm{Au}$ & 31 \\
\hline & 228.0 & & 229.3 & 232.2 & $\mathrm{Au}$ & 32 \\
\hline & & & 229.1 & 232.5 & $\mathrm{Au}$ & 33 \\
\hline & & & & 232.3 & $\mathrm{Au}$ & 34 \\
\hline & & & & 233.3 & C & 35 \\
\hline & & & & 232.7 & C & 36 \\
\hline & & & & 232.6 & $\mathrm{Au}$ & 37 \\
\hline & & & & 232.8 & Au & 38 \\
\hline \multirow[t]{3}{*}{$\mathrm{C} 1 \mathrm{~s}$} & & 282.0 & & & & 39 \\
\hline & & 282.5 & & & Au & 24 \\
\hline & & 282.7 & & & C & 40 \\
\hline \multirow[t]{7}{*}{$01 \mathrm{~s}$} & & & 529.9 & 530.2 & $\mathrm{Au}$ & 33 \\
\hline & & & 530.2 & & $\mathrm{Au}$ & 27 \\
\hline & & & 530.6 & 530.5 & Au & 30 \\
\hline & & & 530.7 & 530.3 & $\mathrm{Au}$ & 32 \\
\hline & & & & 531.1 & c & 35 \\
\hline & & & & 531.3 & $\mathrm{Au}$ & 34 \\
\hline & & & & 530.4 & $\mathrm{Au}, \mathrm{Cu}$ & 37 \\
\hline
\end{tabular}

sample using a single, well-separated, low-BE component of the $\mathrm{Ag} 3 \mathrm{~d}$ peak:

$$
G(\alpha)=\frac{I_{\mathrm{Ag} 3 d}(\alpha)}{I_{\mathrm{Ag} 3 \mathrm{~d}}(0)}
$$

The measured function $G(\alpha)$ was close to that obtained on a clean, sputtered Si sample. ${ }^{44}$
The thickness of the contamination layer on the sheet of molybdenum has been measured. The XPS analysis of the Mo tip is rather doubtful because a correct takeoff angle evaluation on a very small measuring spot is difficult.

To obtain the intensities of the Mo peaks, we simulated the Mo $3 \mathrm{~d}$ spectra at take-off angles of $0^{\circ}, 10^{\circ}, \ldots$,

Table 2. Evaluation of carbon, oxygen and molybdenum concentrations in surface region of Mo STM tip and Mo sheet

\begin{tabular}{|c|c|c|c|c|}
\hline & \multirow[b]{2}{*}{ Method } & \multicolumn{3}{|c|}{ Atomic concentration (\%) } \\
\hline & & Carbon & Oxygen & Molybdenum \\
\hline Molybdenum tip as-received & $\begin{array}{l}\text { AES } \\
\text { XPS }\end{array}$ & $\begin{array}{l}55.5 \pm 7.8^{\mathrm{a}} \\
37.6\end{array}$ & $\begin{array}{l}22.3 \pm 8.3^{a} \\
15.6\end{array}$ & $\begin{array}{l}22.1 \pm 4.0^{\circ} \\
46.9\end{array}$ \\
\hline Molybdenum sheet as-received & $\begin{array}{l}\text { AES } \\
\text { XPS }\end{array}$ & $\begin{array}{l}50.7 \bullet 5.5^{b} \\
36.0\end{array}$ & $\begin{array}{l}23.6 \pm 9.1^{b} \\
31.3\end{array}$ & $\begin{array}{l}25.6 \pm 4.4^{b} \\
32.7\end{array}$ \\
\hline $\begin{array}{l}\text { Molybdenum sheet as-received } \\
\text { angle-resolved }\left(\alpha=60^{\circ}\right)\end{array}$ & XPS & 43.1 & 28.6 & 28.3 \\
\hline
\end{tabular}

Table 3. Calculated concentrations (at.\%) of Mo, $\mathrm{C}$ and $\mathrm{O}$ in different compositions from XPS measurements on Mo sheet

\begin{tabular}{|c|c|c|c|c|c|c|c|c|c|}
\hline \multirow[b]{2}{*}{ Element } & \multicolumn{3}{|c|}{ Mo 3d } & \multicolumn{4}{|c|}{$C$ 1s } & \multicolumn{2}{|c|}{$01 \mathrm{~s}$} \\
\hline & Mo & $\mathrm{Mo}_{2} \mathrm{C}$ & $\mathrm{MoO}_{2}$ & $\mathrm{Mo}_{2} \mathrm{C}$ & Graphite & $\mathrm{co}$ & Aliphatic & $\mathrm{Mo}_{2} \mathrm{O}$ & $\mathrm{O}_{2}, \mathrm{CO}$ \\
\hline Mo & 20.6 & 3.6 & 8.5 & & & & & & \\
\hline c & & & & 1.3 & 14.3 & 4.7 & 17.7 & & \\
\hline 0 & & & & & & & & 19.0 & 12.3 \\
\hline
\end{tabular}



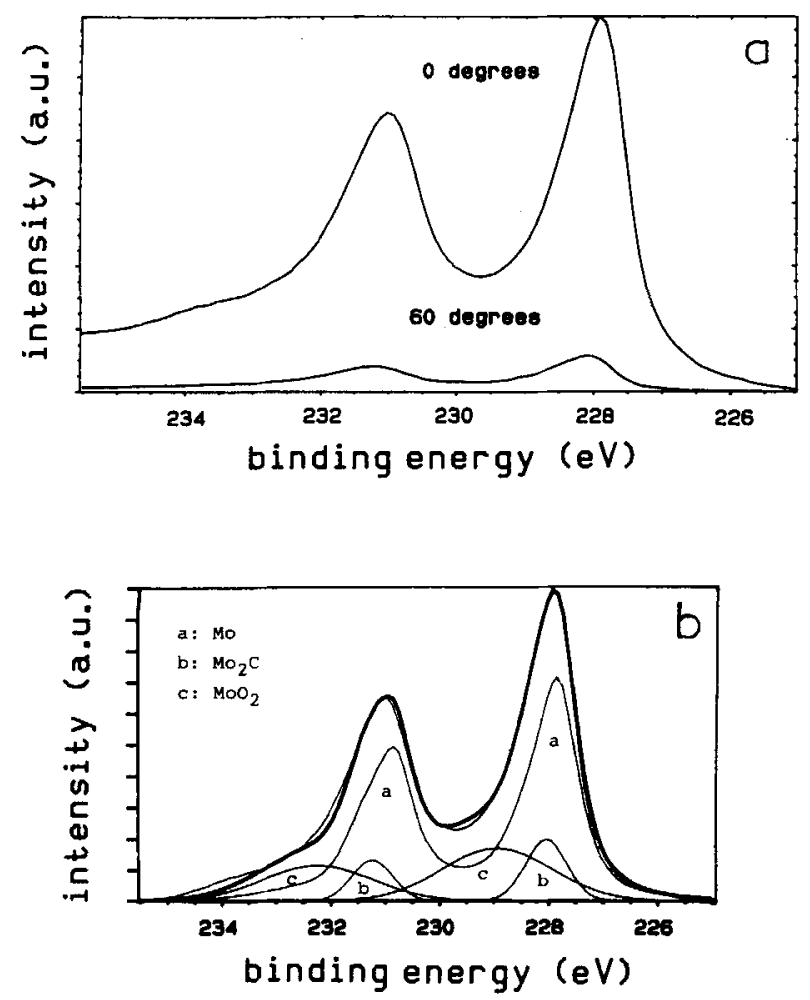

Figure 7. (a) Mo 3d XPS peaks of Mo sheet at photoelectron take-off angles of $0^{\circ}$ and $60^{\circ}$. (b) Simulation of Mo 3d XP spectrum at $0^{\circ}$ take-off angle.

$70^{\circ}$. In Fig. 7(a) two XPS spectra of the Mo 3d peak measured on the sheet are shown, taken at electron take-off angles $\alpha$ of $0^{\circ}$ and $60^{\circ}$. The deconvoluted spectrum of Mo $3 \mathrm{~d}$ at $0^{\circ}$ take-off angle is presented in Fig. 7(b). The thinner lines ' $b$ ' and ' $c$ ' represent the Mo 3d doubtlets of $\mathrm{Mo}_{2} \mathrm{C}$ and $\mathrm{MoO}_{2}$, while line ' $\mathrm{a}$ ' describes the pure Mo $3 \mathrm{~d}$ doublet of molybdenum. The sum of these Mo lines is given as the thicker solid line.

The thickness calculation has been performed with the Mo 3d low-BE component (the line with the highest intensity), normalized to the intensity at normal take-off angle and divided by the measured function $G(\alpha)$.

The result of the application of Eqn (1) for the surface layer thickness determination is presented in Fig. 8. In the co-ordinate system

$$
\ln \frac{N(\alpha)}{G(\alpha)} v s \cdot\left(1-\frac{1}{\cos \alpha}\right)
$$

a straight line with correlation factor 0.998 was obtained. The calculated value of $d / \lambda_{\text {Mo 3d, surf }}$ was 2.20 . Taking a value of $\lambda_{\text {Mo } 3 d, \text { surf from the literature, }}{ }^{45,46}$ we can estimate the thickness $d$ to be $6.8 \mathrm{~nm}$, which is in good agreement with the AES experimental result obtained on the sheet of molybdenum $(8.0 \pm 1.5 \mathrm{~nm})$.

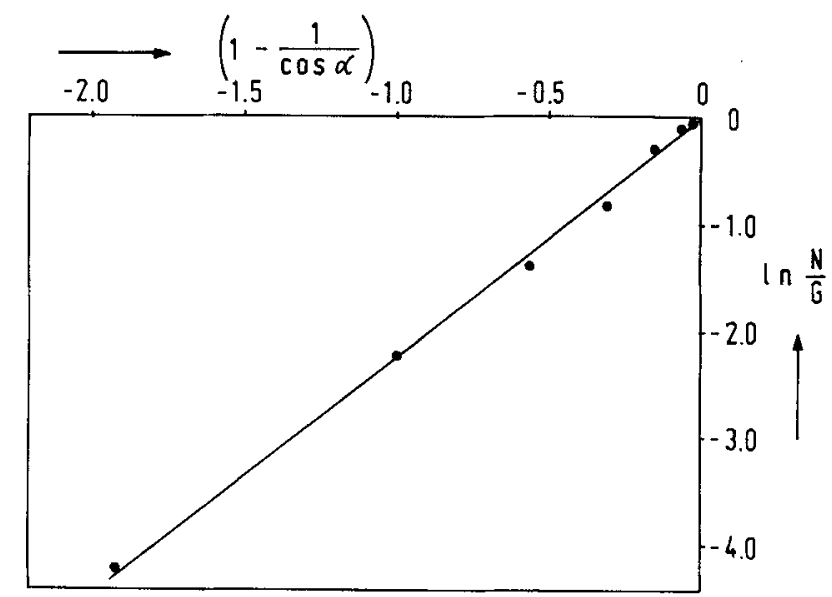

Figure 8. Examination of Eqn (1) for the thickness of the contamination layer on molybdenum determined using ARXPS measurements. The points represent experimental results while the straight line is the result of the fit.

\section{CONCLUSIONS}

The following conclusions can be drawn.

(1) A combination of XPS, AES, Auger line profiling and multiple-point $\mathrm{Ar}^{+}$-ion-sputtering Auger depth profiles appears to be very useful for qualitative and quantitative analysis of the surface contamination of molybdenum STM tips. This is helpful for a preliminary selection of good-performance tips.

(2) Graphite, molybdenum carbide, carbon monoxide and hydrocarbons were found as the main carbon contaminants on the molybdenum tip surface.

(3) Chemisorbed oxygen, carbon monoxide and molybdenum oxide were revealed as oxygen contaminants on the Mo tip surface.

(4) Higher concentrations of carbon and oxygen were detected on top of the Mo tip.

(5) The thickness of the contamination layer on the Mo tip was estimated to be $13.5 \pm 1.0 \mathrm{~nm}$ using $\mathrm{Ar}^{+}$. ion-sputtering Auger depth profile measurements. The contamination layer on the Mo tip was found to be much thicker than that reported on a W tip $(1 \pm 3 \mathrm{~nm})^{6,47}$

(6) The thickness of the oxide-carbon layer on an Mo sheet was evaluated to be $8.0 \pm 1.5$ and $6.8 \mathrm{~nm}$ using AES and absolute ARXPS measurements respectively.

\section{Acknowledgement}

The authors would like to thank Mr B. Otten for preparing the SEM images.
1. G. Binning, H. Rohrer, Ch. Gerber and E. Weibel, Phys. Rev. Lett. 49, 57 (1982).

2. G. Binning and H. Rohrer, Helv. Phys. Acta 55, 726 (1982).

3. Y. Kuk and P. J. Silverman, Appl. Phys. Lett. 48, 1597 (1986).
4. D. K. Biegelsen, F. A. Ponce, J. C. Tramontana and S. M. Koch, Appl. Phys. Lett. 50, 696 (1987).

5. J. H. Musselman and P. E. Russell, J. Vac. Sci. Technol. A 8 , 3558 (1990). 
6. W. Lisowski, A. H. J. van den Berg, G. A. M. Kip and L. J. Hanekamp, Fresenius Z. Anal. Chem. 341, 196 (1991).

7. R. J. Colton, S. M. Baker, R. J. Driscoll, M. G. Youngquist, J. D. Baldeschwieler and W. J. Kuiser, J. Vac. Sci. Technol. A 6. 349 (1988).

8. J. Garaes, F. Kragh, K. A. Morch and A. R. Thölén, J. Vac. Sci. Technol. A 8, 441 (1990).

9. T. Tiedje, J. Varon, H. Deckman and J. Stokes, J. Vac. Sci. Technot. A 6, 372 (1988)

10. H. Morikawa and K. Goto, Rev. Sci. Instrum. 59, 2195 (1988).

11. S. Morishita and F. Okuyama, J. Vac. Sci. Technol. A 9, 167 (1991).

12. Detectability Limits for Auger Analysis, PHI Tech. Bull. T8401. Physical Electronics Industries, Perkin-Elmer (May 1984).

13. H. E. Bishop, in Methods of Surface Analysis, ed. by J. M. Walls, Chap. 4, p. 108. Cambridge University Press, Cambridge (1989).

14. M. T. Anthony, in Practical Surface Analysis by Auger and $X$-ray Photoelectron Spectroscopy, ed. by D. Briggs and M. P. Seah, Appendix 1, p. 431. Wiley, Chichester (1983).

15. Kratos Analytical Instruments, XSAM 800-Operators Handbook, Volume 3.

16. I. Kojima and M. Kurahashi, J. Electron Spectrosc. Relat. Phenom. 42, 177 (1987).

17. L. E. Davis, N. C. MacDonald, P. E. Palmberg, G. E. Riach and R. E. Weber, Handbook of Auger Electron Spectroscopy. Perkin-Elmer Corporation, Physical Electronics Division, Eden Prairie, MN (1978).

18. K. A. Gschneider, Solid State Phys. 16, 275 (1964).

19. M. P. Seah, Thin Solid Films 81, 279 (1981).

20. H. H. Andersen, Appl. Phys. 18, 131 (1979).

21. S. Strop, Spectrochim. Acta B 40, 745 (1985)

22. T. W. Haas, J. T. Grant and G. J. Dooley, J. Appl. Phys. 43, 1853 (1972).

23. C. Teuret-Noel, J. Verbist and Y, Gobillon, J. Microsc. Spectrosc. Electron 1, 255 (1976).

24. W. A. Brainard and D. R. Wheeler, J. Vac. Sci. Technol. 15, 1800 (1978)

25. D. S. Zingg, L. E. Makovsky, R. E. Tischer, F. R. Brown and D. M. Hercules, J. Phys. Chem. 84, 2898 (1980).

26. Handbook of $X$-ray Photoelectron Spectroscopy. Perkin-Elmer Corporation, Physical Electronics Division, Eden Prairie, MN (1979).
27. B. Brox and I. Olefjord, Surf. Interface Anal. 13, 3 (1988).

28. R. Nyholm and N. Mártensson, J. Phys. C: Solid State Phys. 13, L279 (1980)

29. S. O. Grim and L. J. Matienzo, Inorg. Chem. 14, 1014 (1975).

30. R. J. Colton, A. M. Guzman and J. W. Rabalais, J. Appl. Phys. 49, 409 (1978).

31. C. D. Wagner and J. A. Taylor, J. Electron Spectrosc. Relat. Phenom. 20, 83 (1980)

32. K. S. Kim, W. E. Baitinger, J. W. Amy and N. Winograd, J. Electron Spectrosc. Relat. Phenom. 5, 531 (1974)

33. D. D. Sarma and C. N. R. Rao, J. Electron Spectrosc. Relat. Phenom. 20, 25 (1980).

34. P. Gajardo, D. Pirotte, C. Defosse, P. Grange and B. Delmon, J. Electron Spectrosc. Relat. Phenom. 17, 121 (1979)

35. V. I. Nefedov, M. N. Firsov and I. S. Shaplygin, J. Electron Spectrosc. Relat. Phenom. 26, 65 (1982).

36. J. L. G. Fierro, E. Salazar and J. A. Legarreta, Surf. Interface Anal. 7, 97 (1985).

37. J. Haber, T. Machej, L. Ungier and J. Ziôłkowski, J. Solid State Chem. 25, 207 (1978).

38. Y. Iwasawa and S. Ogasawara, J. Chem. Sac., Faraday Trans. 175,1465 (1979).

39. E. Robinson, Handbook of Spectroscopy, CRC Press, Cleveland, $\mathrm{OH}(1974)$

40. L. Ramqvist, K. Hamrin, G. Johansson, A. Fahlman and C. Nordling, J. Phys. Chem. Solids 30, 1835 (1969).

41. K. Hamrin, G. Johansson, U. Gelius, C. Nordling and K. Siegbahn, Phys. Scr. 1, 277 (1970).

42. U. Gelius, P. E. Hedén, J. Hedman, B. J. Lindberg, R. Manne, R. Nordberg, C. Nordling and K. Siegbahn, Phys. Scr. 2, 70 (1970).

43. C. R. Brundle, Surf. Sci. 48, 99 (1975).

44. W. A. M. Aarnink, A. Weishaupt and A. van Silfhout, App/. Surf. Sci. 45, 37 (1990), and references cited therein.

45. M. P. Seah and W. Dench, Surf. Interface Anal. 1, 2 (1979).

46. D. R. Penn, J. Electron Spectrosc. Relat. Phenom. 9, 29 (1976).

47. W. Lisowski, A. H. J. van den Berg, L. J. Hanekamp and A. van Silfhout, Microchim. Acta, submitted. 